\title{
PRIORITIZATION OF QUALITY CARE CRITERIA TO DELIVER QUALITY SERVICE USING DEMATEL
}

\author{
Raja Rub Nawaz 1 \\ PAF-KIET Karachi \\ Dr. Rafique Ahmed 2 \\ Bahria University, Karachi \\ Sajida $\operatorname{Reza}^{3}$ \\ BUITEMS, Quetta
}

\begin{abstract}
Purpose:-Hospitals are very vital as an element in Quality Care delivery and their evaluation in these terms on perpetual basis are much needed as these organizations contribute in improving health outcomes for general people. Hospitals, especially privately owned, are also run like businesses these days to remain competitive in the respective arena. The environment and situation faced by many hospitals are often complicated and which definitely requires insightful solutions to steer the direction of these businesses. This study was focused on the application of group decision-making tool, DEMATEL as one of the valid methods in Multi-Criteria Decision Making (MCDM). Methodology:- The study was exploratory in nature and efforts were made to justify by highlighting the criteria prioritization procedure to be undertaken by any healthcare organization. A slight deviation from standard four-steps of DEMATEL, a course of action was created in shape of eight-step procedure to exhibit a practical approach rather than mathematical theory approach. In order to make it more empirical in nature, a five-stage research framework was also devised and acted upon with the help of three separate questionnaires. Avedis Donabedian's (1988) Quality Care framework was followed and multiple variables were devised, importance ratings were collected from patients on these devised variables and after reduction of variables in to manageable latent factors, called criteria in the study, DEMATEL method was applied to depict the prioritization of Quality Care criteria for the delivery of quality service via digraph. Findings:-The graphical representation through digraph showed that criteria were vertically divided in two halves as C1, C5, and C4 are shown as criteria influencing the lower half criteria C3, C6, and C2. The horizontal span of digraph reflected the importance of criteria prioritized and showed Cl criterion as the most important and C2 criterion with least importance.

Implications:-The prioritization of the criteria along with their cause and effect distribution gave an insight into the constitution framework of localized healthcare services of Karachi, Pakistan.
\end{abstract}

Keywords : Quality Care, DEMATEL, Quality Service, MCDM

\section{Jel Classification: D920, E220, F210}

* The material presented by the author does not necessarily portray the viewpoint of the editors and the management of the Institute of Business \& Technology (IBT)

1. Raja Rub Nawaz

2. Dr. Rafique Ahmed

3. Sajida Reza

: rak@bimcs.edu.pk

C IBTJBS is published by the Institute of Business and Technology (IBT).

Main Ibrahim Hydri Road, Korangi Creek, Karachi-75190, Pakistan. 


\section{INTRODUCTION}

For people the health quality care has been the dominant issue in their lives. They require mechanisms that should operationalize with cardinal objectives like protection, care and promotion of health quality innately delved in to the systems that work for them by the management. Deviation from these justified objectives usually results in mediocre hospital care which brings out the poor quality of health and simultaneously affecting the social and economic weave of people. Unfortunately, this departure is generally prevalent throughout.

Hospitals are considered to be very vital in playing their central quality care role in any economy. Evaluation of hospitals irrespective of private and public, as one of the leading element of quality care dominion, is supportive in development of general understanding concerning hospital care quality which in turn contributes to the canon of improving health outcomes for general people in any micro and macro economies.In order to conceptualize the efforts for resolution of poor health quality care issues, perpetuity as an action should be undertaken for constant, continuous, and sustainable quality care in hospitals. Decision makers of any hospital at micro level of the economy should monitor, assess and improve hospital performance management.

The aim and context of this study is to present a quality care framework presented by AvedisDonabedian $(1966,1980$, and 1988). Based on this, the study is focused to develop the localized variables/attributes for Donabedian's framework utilizing the thought process of relevant decision makers of the industry (doctors/practitioners), acquiring, reducing, and summarizing the importance ratings from general people (patients) on developed localized attributes, and ultimately prioritizing the reduced set of summarized attributes by employing one of suitable scientific techniques of prioritization with the help of doctors and practitioners.

\section{LITERATURE REVIEW}

Hospitals in any society are deemed as necessary. Its role in any health quality care domain is vital to foster a healthy society. Hospital's performance evaluation should be carried out on a continuous basis.

\subsection{Quality Care}

World Health Organization (2000) proposed four functions that may be adopted by any active health quality care mechanism laid out for general public and they are: a) provision of services; b) development, generation and acquisition of physical and human resources that help services to be deliverables; c) resources and funds leveraging to bear the health quality care exigencies, and d) steering the overall direction for all stakeholders involved. Implementation of these four functions in health quality care endorses the altruistic causes of better health achievement, meeting people's expectations, and equity in financial distribution (Murray \&Frenk 2000; WHO 2000).

Quality healthcare improvement along with its precursor, i.e., evaluation of quality 
healthcare, is usually seen as an arduously uphill task and most generally construed as partially surmounted (Brook, McGlynn\&Shekelle 2000). For evaluation of a quality healthcare, AvedisDonabedian (1988) in his seminal paper postulated the three component framework (Fig 1). The basic premises of Donabedian's work balance the stakes of quality healthcare provider (doctors/practitioners) and the receiver as patient (individually and collectively). It simply means that provision of quality healthcare (at technical as well as interpersonal levels) by physicians and the care adopted by patients should be interfaced together. It's a joint responsibility function of any quality healthcare system.

Donabedian (1988) conceptualized his framework for the assessment of quality of healthcare with three components viz: Structure, Process, and Outcome (Fig 1). There have been numerous studies done on the use of Donabedian's framework to evaluate the healthcare system's performance in the dimension of quality care (Andaleeb 1998; Chow-Chua \& Goh 2002; Eggli\&Haflon 2003; Block 2006).

In Donabedian's (1988) work, first component structure provides the direction towards the resources (material and human) and quality healthcare organization structure. Material resources include facilities, equipment, budget etc. and human resources entail number and qualification of practitioners and personnel involved in quality care delivery. The sub-component which is organizational structure detail on medical staff organization, peer-review methodologies etc. The second component process highlights the activities and tasks handled by healthcare staff members during deliverance of services to patients. Van Peursem at el (1995) highlighted that process as a component epitomizes an interrelationship aspect envisaging the medical, social and psychological interactions between quality care providers and patients and ultimately patients' satisfaction as resultant to it. The third and the last component, outcome, refers to a patient's satisfaction and behavioral shift due to effect of quality healthcare provided (Donabedian 1988).

\subsection{Group Decision Making}

The world in shape of any day's situational context is not construed in simple terms generally. The environment and situation faced by many businesses are often complicated and which definitely requires insightful solutions to steer the direction of these businesses. These solutions or strategies begin with structuring models by enveloping the various elements delineating into components and their relationships (Sharma et al 1995). Structural modeling is one of the ways to solve a complex problem and it is being applied extensively as it is deemed a befitting basis for managing decision criteria along with the use of these criteria to come up with decision structures.

Practically effective decision making for solving complex and confusing problems borne with multiple criteria, and collecting group knowledge from experts is a mandatory exercise which involves multiple criteria decision making (MCDM) methods. There are several methods under the domain of MCDM to solve such problems and they are namely: ELECTRE, TOPSIS, AHP etc. (Zanakis et al 1998). MCDM methods are very useful where structural model of evaluation of multiple criteria pre-exist. DEMATEL is also considered to be a comprehensive method for MCDM related issues (Tzeng et al 2011). 


\subsection{Dematel}

The Battelle Memorial Institute developed the DEMATEL method via a research project undertaken at Geneva Research Centre (Gabus\&Fontela 1972, 1973). The acronym DEMATEL stands for Decision Making Trial and Evaluation Laboratory. It is based on digraphs separating graphically or visually the criteria under discussion in cause and effect groups, hence its basis is on graph theory. This separation of cause groups and effect groups of multiple criteria visually depicts the inherent causal relationships among them. Tzeng and Huang (2011) emphasized the importance of application of graph theory enabling the decision makers (experts) to discover and explore complex problems via clear and meaningful visual graphs out of mathematical calculations.

The DEMATEL method procedure consists of 4 steps originally (Hori \& Shimizu 1999; Chung-Wei \&Gwo-Hshiung 2009). The following procedural steps are a slight deviation as used in this study.

\section{Step 1: Identification of Decision Objectives and Experts Committee Formation}

First and foremost, identification of decision objectives is carried out and then a committee of relevant industry experts is created to acquire the group decision making knowledge for the undertaken decision making problem(s).

Step 2: Extraction of Evaluation Criteria Along with Influence Rating Scale Design This is an additional and deviated step to standard DEMATEL four-step methodology as postulated by researchers (Hori \& Shimizu 1999; Chung-Wei \&Gwo-Hshiung 2009). This additional step reduces and summarizes the greater number of variables to less number of criteria to be manageable for later steps of DEMATEL. Factor analysis analytic approach was adopted for the reduction of variables. All important criteria sets are developed or extracted in this step. Depending on the extraction techniques the criteria usually have built-in causal relationships or inter-dependencies which may be complicated at times. So for the reason to lessen this, the influence rating scale is designed to reflect experts' judgments. The direct influence between any two criteria is evaluated by assigning a rating score representing " 0 " for no influence; " 1 " for low influence; " 2 " for moderate influence; " 3 " for high influence; and "4" for extremely high influence.

For every single expert, a $\mathrm{n} \times \mathrm{n}$ non-negative matrix is constructed, called answer matrix $\mathrm{X}^{\mathrm{k}}$

$$
\mathrm{X}^{\mathrm{k}} \text { with } 1<\mathrm{k}<\mathrm{h}
$$

Where $\mathrm{h}=$ total experts

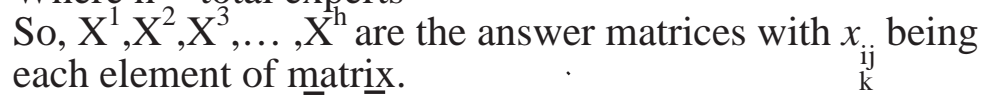

\section{Step 3: Calculate the Average Matrix}

Once all the matrices for all experts $\mathrm{h}$ are created, then we can calculate the average matrix A by averaging the experts' score matrices as explained above. The row column element $(i, j)$ in matrix $\mathbf{A}$ is denoted by $a_{-} i j$ and is calculated by the formula: 


$$
a_{i j}=\frac{1}{h} \sum_{k=1}^{h} x_{i j}^{k}
$$

\section{Step 4: Calculate the Normalized Matrix}

The normalized initial direct-influence matrix $\mathbf{D}$ is calculated as:

where

$$
\mathbf{D}=\mathbf{s} \cdot \mathbf{A}
$$

$$
s=\operatorname{Min}\left[\frac{1}{\max _{1 \leq i \leq n} \sum_{j=1}^{n} a_{i j}}, \frac{1}{\max _{1 \leq j \leq n} \sum_{i=1}^{n} a_{i j}}\right]
$$

\section{Step 5: Calculate the Total Influence Matrix}

After applying above, $\mathbf{T}$, total-influence matrix $\mathbf{T}$ is developed by Eq. 3 below:

$$
\mathrm{T}=\mathrm{D}(\mathrm{I}-\mathrm{D})^{-1}
$$

Eq. 3

Where $I$ is identity matrix.

Step 6: Compute the Total Effects Given or Received by Each Criteria From total influence matrix $\mathbf{T}$, the row sums and column sums are calculated from using Eq. 4 and Eq. 5 denoted by vectors $g$ and $r$ respectively. Moreover, the effects given or received are estimated from Eq. 4 - Eq. 7.

$$
\begin{gathered}
T=t_{i j}, \quad i, j=1,2,3, \ldots, n \\
g=\sum_{j=1}^{n} t_{i j}
\end{gathered}
$$

Where

$g$ denotes the effect given by the criterion $i$

$$
r=\sum_{i=1}^{n} t_{i j}
$$

Where

$r$ denotes the effects received by the criterion $i$

After having done the calculations by employing equations 4 and 5, the total effects given and received are calculated by using equations 6 and 7 .

Total effects given $=\boldsymbol{p}=\mathrm{g}+\mathrm{r}$

Eq. 6 
The value $\boldsymbol{p}$ explains the total effects both given and received by criterion $i$. On the other hand the net effect of criterion $i$ is denoted by $\boldsymbol{q}$. If $\boldsymbol{q}$ is positive, criterion $\mathrm{i}$ is a net "giver" or "cause" and when qis negative, criterion $i$ is a "receiver" (Tzeng et al 2007; Liou et al 2007; Yang et al 2008; Lee et al 2009).

\section{Step 7: Calculate the Threshold Value}

Using Eq. 8, elements of matrix T are averaged out and this average value is called the threshold valuea. Averaging out removes minor effects in matrix T. (Yang et al 2008; Chung-Wei \&Gwo-Hshiung 2009).

Where

$$
\alpha=\frac{\sum_{i=1}^{n} \sum_{j=1}^{n}\left[t_{i j}\right]}{N} \quad \text { Eq. } 8
$$

$\mathrm{N}$ denotes the total number of elements (rows $\times$ columns) of matrix $\boldsymbol{T}$.

\section{Step 8: Construct Cause and Effect Digraph}

Complex inter-relationship between the criteria can easily be shown by constructing a cause and effect digraph. The digraph provides necessary information to enable decision makers to judge or explore the important criteria which "influence" or "are influenced" by other criteria. The digraph is constructed by mapping the columns of values $\boldsymbol{p}$ and $\boldsymbol{q}$ (see Eqs. 6 and 7 above). Criteria effect that will be greater than this threshold value are chosen and depicted in cause and effect digraph (Chung-Wei \& Gwo-Hshiung 2009).

\section{Research Framework}

This study followed the five stage research framework (Figure 2).

\section{RESEARCH METHODOLOGY}

The research commenced from identification of quality care criteria based on framework postulated by Donabedian (1988). These criteria were then rated upon in terms of importance by the patients availing quality care services. Using the principal axis factoring extraction method of Factor Analysis, the criteria were then reduced and summarized into manageable number of criteria so that DEMATEL method could be applied on them after judgments of healthcare experts were collected on the final set of factors.

\section{Stage 1: Identification of Quality Care Criteria}

AvedisDonabedian's (1988) proposed quality care framework consisting three components viz. Structure, Process, and Outcome. Albeit, Donabedian's (2005) recent work highlighted seven dimensions of quality care assessment, this study resorted to his original seminal work to identify the quality care criteria within the contextual locale of city of Karachi, Pakistan. A simple questionnaire (Q1) was developed mentioning the three components in three columns with brief conceptual definitions just under the 
column heads. Each column entailed with blank lines, for healthcare experts, to think and develop the criteria for each component. Fifteen experts were contacted from five hospitals to acquire the responses on Q1. For criteria identified, sifted and filtered after Q1 see Figure 3.

\section{Stage 2: Collection of Patients' Importance Ratings on Chosen Criteria}

Once the criteria list was developed through healthcare experts, patient's perspective on these criteria viz. importance was needed. For this purpose a second questionnaire (Q2) was designed by taking criteria from stage 1 as attributes and seeking rating response on each criterion on a five-level importance rating scale. The scale ranged from 1 as "highly unimportant" to 5 being "highly important" with intermediating degrees in-between.

Stage 3: Reduction or Summarization of Importance Rating Responses of Patients Then the criteria were reduced or summarized into meaningful factors through exploratory factor analysis employing principal axis factoring extraction method. Extracted factors were named and interpreted as per propositions suggested by Comrey and Lee (1992). After naming the factors a structural diagram of factors (taken as attributes) and variables (extracted factors as criteria) was constructed (Figure 4).

\section{Stage 4: Collection of Influence Rating Judgments from Healthcare Experts}

In stage 4, another questionnaire (Q3) was developed for seeking judgments or assessments from fifteen healthcare experts on pair-wise comparisons of important criteria (from stage 3) based on influence scale (see Table 1). The group of experts evaluated the criteria influences and directions, highlighting the measurement of relationship between them as per experts' objective judgments.

\section{Stage 5: Applying DEMATEL and Constructing the Resultant Digraph}

Once the influence rating judgments from healthcare experts were collected, DEMATEL method is applied with the addition of factor analytic procedure included in all 8 steps which are highlighted in literature review above.

Step 1: Identification of Decision Objectives and Experts Committee Formation. The decision making goal undertaken in this study was set as "prioritization of quality care criteria to deliver quality service". A committee of experts was formed consisting fifteen healthcare experts in capacity ranging from general practitioners to specialized surgeons to managing directors from known hospitals of city of Karachi, Pakistan.

\section{Step 2: Extraction of Evaluation Criteria Along with Influence Rating Scale Design.}

Once the variables under components of Donabedian's (1988) framework were collected as explained above, the factor analysis protocol was adopted to identify variables collected to primary latent variables to which patients adhere perceptually. Principal axis factoring extraction method along with orthogonal rotation was used for 27 variables and their importance ratings were gathered via questionnaire (Q2) from 281 patients. The acceptability for factor analysis was scrutinized using several known criteria of factor analysis protocol. All of 27 variables correlated with minimum .3 with 
at least one other variable, proposing the acceptability for further analysis. The KaiserMeyer-Olkin measure of sampling adequacy $(\mathrm{KMO}=.824)$ proved that sample collected is acceptable for factor analysis and also highlighted that relationships strength within variables used was high enough from the recommended value of .6 (Hair et al 2006). The Bartlett's test of sphericity was significant $\left(X^{2}(351)=1631.71, \mathrm{p}<0.001\right)$. Lastly, the communalities table also confirmed that each item shared some common variance with the other variable as communalities' values were all above .3. From factor analysis protocol run, 6 factors with eigenvalues greater than one were extracted.

The committee of healthcare experts came up with 27 criteria and with EFA these criteria were grouped, reduced and summarized to six criteria and these six criteria were named, consequently.

The first criterion was named as patient focused practices as it consisted of all those factors which revolve around patients and their expectations with any healthcare organization such as prompt complaints handling, satisfactory staff-patient ratio, punctual consultation with practitioners, accurate maintenance of patient records, future preference for treatments, easy procedures for registration, and correct initial diagnosis.

The second criterion was summarized and named as confidence and trust building mechanisms that must exist in any healthcare organization for its patients and this criterions was based on factors such as affordable services, presence of qualified medical staff, effective treatments, practitioners' openness to suggestions by patients, satisfactory treatments provided, and resultantly patient referrals to others.

The third criterion, pre-treatment procedural amenities, summarized the factors that were more related to perceptions of patients e.g. case-history maintenance, presumption of knowledgeable staff, structurally clear and wide entrances and exits, prompt treatment procedure without any delay, and easy appointment system for patients.

The fourth criterion was named as staff amicability by studying the factors that were related with personal interactions of patients with organization's medical staff and practitioners responsible for delivering the quality care services to them, such as friendly attitude and behavior of staff, clean and hygienic healthcare environment, and portrayal of sympathetic approaches to patients.

The fifth criterion was labeled as diagnostic systems and it was summarized from factors that exist physically and are visually experienced by patients visiting a hospital. These factors were necessary medical equipment, reliable diagnostic labs, complete information about treatment procedure, and accurate billings.

The last and the sixth criterion was named as peripheral benefits due to the factors that were grouped on the basis of patients' perceptual presumptions e.g. healthcare organization's effort to avoid un-necessary stay for patients at hospital, and clean medical equipment. 


\section{Step 3: Calculate the Average Matrix}

Using the collected influence ratings judgments by fifteen healthcare experts, influence matrices were constructed for each and every expert's judgments. Influence matrix for expert 1 is only shown here as an example (Table 2).

All fifteen experts' judgments were collected and likewise fifteen influence matrices were constructed. Then Eq. 1 was applied to obtain the average matrix A (Table 3). This matrix A is just the average matrix of all experts' assessments/judgments on criteria under discussion.

\section{Step 4: Calculate the Normalized Matrix}

Once the average matrix is calculated, the normalized matrix D (Table 4) was calculated by using Eq. 2.

\section{Step 5: Calculate the Total Influence Matrix}

After the normalized matrix, using Eq. 3, the total influence matrix T is obtained (Table $5)$.

Step 6: Compute the Total Effects Given or Received by Each Criteria The total effects table (Table 6) was constructed to create the input data for DEMATEL digraph by using Eq. 4 to Eq. 7.

\section{Step 7: Calculate the Threshold Value}

The threshold value a was calculated by employing Eq. 8. The equation was operated as averaging out the elements of matrix $T$ by taking $N$ as $36(6 \times 6)$. The a value came out to be 0.4039 .

\section{Step 8: Construct Cause and Effect Digraph}

Then the causal digraph (Figure 5 below) was constructed by mapping the columns of values $\mathrm{p}$ and $\mathrm{q}$ (Table 6). Prioritization of Quality Care criteria is depicted by the figure 5 . The further a criterion is away from left on horizontal axis, the higher is the priority gained by that criterion. The vertical axis divides the chart into top half and bottom half showing cause and effect areas respectively. Criteria effect that will be greater than the threshold value as calculated in step 7 were chosen and shown in cause and effect arrows (Figure 6).

\section{RESULTS AND DISCUSSION}

This study, focusing on Donabedian's (1988) framework, aimed at exploring and prioritizing the localized attributes of quality healthcare. Primarily, attributes deemed essential as perceived by the industry expert were solicited, later on perceptions of the general people about these attributes were entreated and still later, the healthcare experts opined about the importance of these reduced factors. Three questionnaires $(\mathrm{Q} 1, \mathrm{Q} 2$, and Q3) were constructed for three different audiences to collect information.

The industry experts were approached through Q1 to enlist localized attributes on the three criteria (Structure, Process, and Outcome) proposed by Donabedian (1988) 
which are considered important for any healthcare performance management. This list of 27 attributes was then rated upon using Q2 from the general public who were availing different health related services, in terms of their importance. Based on the importance rating of the general public, the list of 27 attributes was reduced and summarized into 6 factors as Q3 and then offered to the health experts for judgmental priority ranking. This procedure was exploited to prioritize the criteria of quality care services for quality service deliverance based on the perceptions of different stakeholders.

Decision making procedure was presented as a cascading process employing Factor analysis and DEMATEL methodology in a unique combination.

Factor analysis aided in reducing and summarizing the 27 attributes into 6 manageable factors. DEMATEL methodology facilitated in obtaining the assessments and judgments of the healthcare experts. The resultant DEMATEL digraph depicts interesting analysis of the experts on the horizontal and vertical axes.

On the horizontal axis, representing the priority importance, among the 6 criteria calculated $(\mathrm{g}+\mathrm{r})$, patient focused practices $(\mathrm{C} 1)$ scored the highest and is considered to be the most prioritized criterion of quality care services. The criterion confidence and trust building mechanisms $(\mathrm{C} 2)$ scored the lowest preceded by peripheral benefits (C6).

The vertical axis depicts the cause and effect area of the criteria $(\mathrm{g}-\mathrm{r})$ divided into two halves. On the upper region, which is the "cause" region, criterion C1 (patient focused practices), C5 (diagnostic systems), and C4 (staff amicability) dominates. It is worth mentioning that $\mathrm{C} 1$ is the only criterion having an effect on the other 5 criteria. The lower region, reflecting the "effect" space has the criterion C3 (pre-treatment procedural amenities), C6 (peripheral benefits), and C2 (confidence and trust building mechanisms).

Although the vertical axis portrays the cause and effect regions, the digraph shows an intertwined relationship where criterion is caused by and effects at least one other criterion except $\mathrm{C} 1, \mathrm{C} 2$, and C6.

\section{CONCLUSION}

The prioritization of the criteria along with their cause and effect distribution gave an insight into the constitution framework of localized healthcare services of Karachi, Pakistan. Results of digraph show that patient focused practices are at the top priority considered by health practitioners, followed by diagnostic systems and pre-treatment procedural amenities. The least priority is given to confidence and trust building mechanisms. This may be interpreted that $\mathrm{C} 2$ may not be directly achieved or aimed at, rather is resultant of the other criteria, when achieved. Concomitantly, the criteria may be a cause of, on one hand and may be caused by different criteria, on the other hand. Though this is not applicable to $\mathrm{C} 1, \mathrm{C} 6$ and $\mathrm{C} 2$ which are patient focused practices, peripheral benefits, and confidence and trust building mechanisms, respectively, as seen from the results. 
PRIORITIZATION OF QUALITY CARE CRITERIA TO DELIVER QUALITY SERVICE USING DEMATEL

This prioritization process enlists factors that are highly favored by the practitioners and may play an important role in the provision of quality healthcare services to the masses.

\section{FURTHER RESEARCH}

Prioritization of Quality care criteria via DEMATEL method necessitated the aspects as empirical framework to establish, operate, maintain, and improvise a system within a hospital. These Quality Care aspects and dimensions must imbibe their strength from adopting prioritization methodology to provide competitive services for sustainable growth on perpetual basis.

To further the research in the domain of this study, government-administered hospitals should be included to broaden sensing their patients' pulse for ameliorative actions to provide the much needed Quality Care services. Adoption and application of other mathematical tools, falling under the broad categories of group decision-making problem solutions (MCDM, MADM, MODM etc.), should be operationalized more as none of the available standard statistical software have these modules or procedures available within them.

\section{ACKNOWLEDGEMENT}

First of all with a profound gratitude, we are thankful to Almighty Allah forgiving us success, knowledge and understanding without which we would not been capable of completing this research paper.

We are also profoundly grateful to all our family members whose endurance and understanding have played a significant role in our success by sacrificing the important family time and supporting us all over the research work.

We are finally thankful to the editor, reviewers and IBT specially who provided us with the opportunity to publish our research paper in this esteemed journal.

\section{REFERENCES}

Andaleeb, S. S. (1998). Determinants of customer satisfaction with hospitals: a managerial model. International Journal of Health Care Quality Assurance,11(6), 181-187.

Block, D. J. (2006). Healthcare outcomes management: Strategies for planning and evaluation. Jones \& Bartlett Learning.

Brook, R. H., McGlynn, E. A., \&Shekelle, P. G. (2000). Defining and measuring quality of care: a perspective from US researchers. International Journal for Quality in Health Care, 12(4), 281-295.

Chow-Chua, C., \& Goh, M. (2002). Framework for evaluating performance and quality improvement in hospitals. Managing Service Quality, 12(1), 54-66.

Chung-Wei, L., \&Gwo-Hshiung, T. (2009). Identification of a Threshold Value for the DEMATEL Method: Using the Maximum Mean De-Entropy Algorithm. InCutting-Edge Research Topics on Multiple Criteria Decision Making Springer Berlin Heidelberg, 789-796. 
Comrey, A. L., \& Lee, H. B. (2013). A first course in factor analysis. Psychology Press. Donabedian, A. (1966). Evaluating the quality of medical care. The Milbank memorial fund quarterly, 166-206.

Donabedian, A. (1980). Methods for deriving criteria for assessing the quality of medical care. Medical care review, 37(7), 653.

Donabedian, A. (1988). Quality assessment and assurance: unity of purpose, diversity of means. Inquiry, 173-192.

Donabedian, A. (1988). The quality of care: How can it be assessed?. Jama, 260(12), 1743-1748.

Donabedian, A. (2005). Evaluating the quality of medical care. Milbank Quarterly, 83(4), 691-729.

Eggli, Y., \& Halfon, P. (2003). A conceptual framework for hospital quality management. International Journal of Health Care Quality Assurance, 16(1), 29-36.

Gabus, A., \&Fontela, E. (1972). World problems, an invitation to further thought within the framework of DEMATEL. Battelle Geneva Research Center, Geneva, Switzerland.

Gabus, A., \&Fontela, E. (1973). Perceptions of the world problematique: Communication procedure, communicating with those bearing collective responsibility. Battelle Geneva Research Centre, Geneva, Switzerland.

Hair, B., \&Babin, A. Tatham (2006) Multivariate Data Analysis.

Hori, S., \& Shimizu, Y. (1999). Designing methods of human interface for supervisory control systems. Control Engineering Practice, 7(11), 1413-1419.

Lee, W. S., Tzeng, G. H., Guan, J. L., Chien, K. T., \& Huang, J. M. (2009). Combined MCDM techniques for exploring stock selection based on Gordon model. Expert Systems with Applications, 36(3), 6421-6430.

Liou, J. J., Tzeng, G. H., \& Chang, H. C. (2007). Airline safety measurement using a hybrid model. Journal of Air Transport Management, 13(4), 243-249.

Murray, C., \&Frenk, J. (2001). World Health Report 2000: a step towards evidencebased health policy. The Lancet, 357(9269), 1698-1700.

Tzeng, G. H., \& Huang, J. J. (2011). Multiple attribute decision making: methods and applications. CRC Press.

Tzeng, G. H., Chiang, C. H., \& Li, C. W. (2007). Evaluating intertwined effects in elearning programs: A novel hybrid MCDM model based on factor analysis and DEMATEL. Expert systems with Applications, 32(4), 1028-1044.

Van Peursem, K. A., Prat, M. J., \& Lawrence, S. R. (1995). Health management performance: a review of measures and indicators. Accounting, Auditing \& Accountability Journal, 8(5), 34-70.

WHO. (2000). The World Health Report 2000: Health System: Improving Performance. Geneva: WHO.

Yang, Y. P. O., Shieh, H. M., Leu, J. D., \&Tzeng, G. H. (2008). A novel hybrid MCDM model combined with DEMATEL and ANP with applications. International Journal of Operations Research, 5(3), 160-168.

Zanakis, S. H., Solomon, A., Wishart, N., \&Dublish, S. (1998). Multi-attribute decision making: A simulation comparison of select methods. European journal of operational research, 107(3), 507-529. 


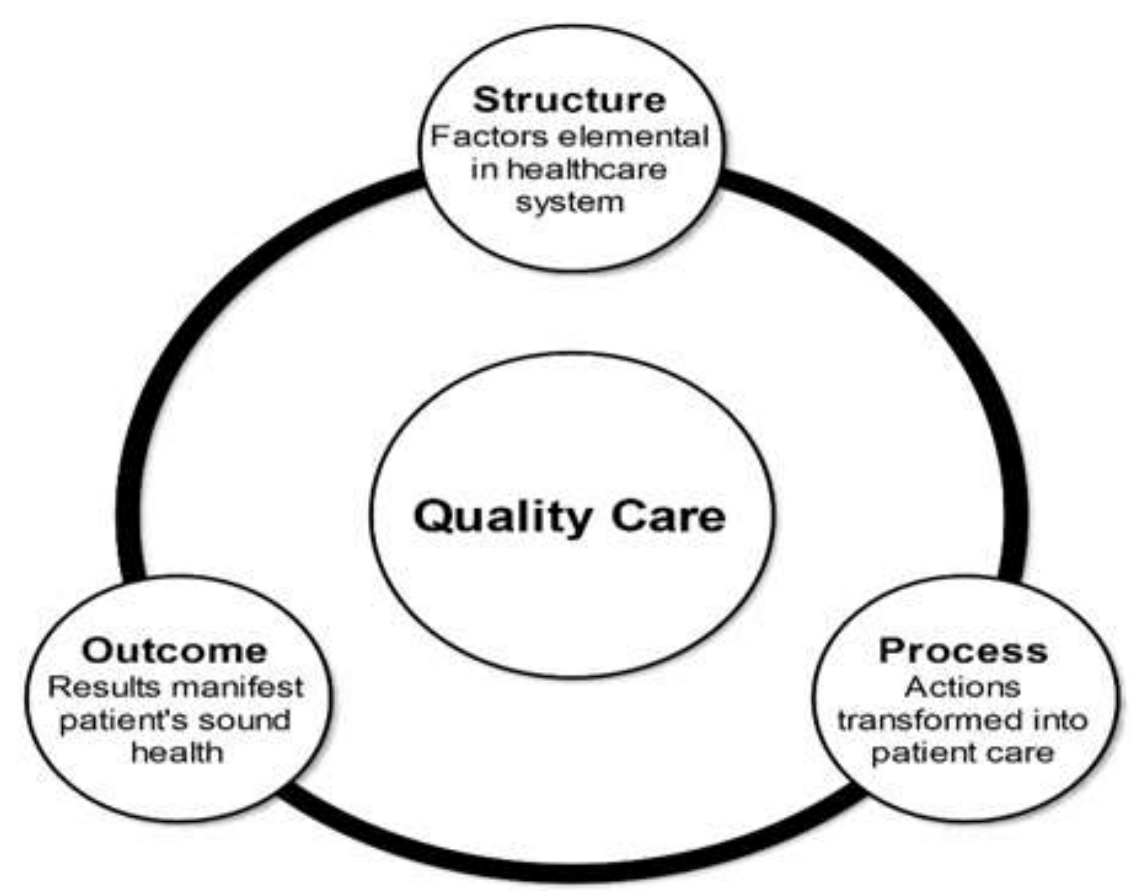

Figure 2.Research framework of the study

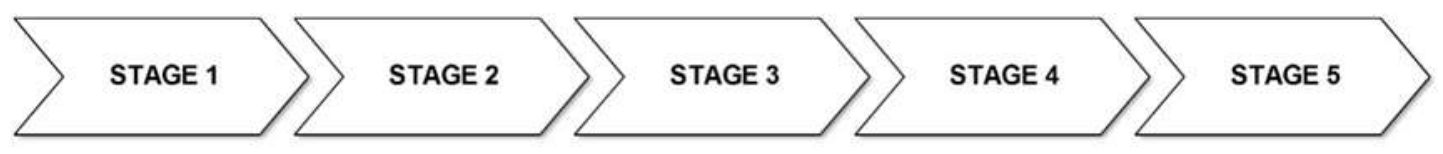

\begin{tabular}{|c|c|c|c|c|}
\hline \multicolumn{5}{|c|}{ RESEARCH FRAMEWORK } \\
\hline $\begin{array}{c}\text { Identification of } \\
\text { Quality care criteria } \\
\text { based on } \\
\begin{array}{c}\text { Donabedian's } \\
\text { (1988) framework by } \\
\text { healthcare experts }\end{array}\end{array}$ & $\begin{array}{c}\text { Collection of } \\
\text { importance ratings } \\
\text { from patients on } \\
\text { identified and } \\
\text { chosen criteria }\end{array}$ & $\begin{array}{c}\text { Reduction of } \\
\text { chosen criteria with } \\
\text { importance ratings } \\
\text { to less number of } \\
\text { extracted factors } \\
\text { (criteria) }\end{array}$ & $\begin{array}{c}\text { Collection of } \\
\text { influence rating } \\
\text { judgments of } \\
\text { healthcare experts } \\
\text { on DEMATEL } \\
\text { questionnaire }\end{array}$ & $\begin{array}{c}\text { Application of } \\
\text { DEMATEL method } \\
\text { and construction of } \\
\text { cause and effect } \\
\text { Digraph }\end{array}$ \\
\hline
\end{tabular}


Raja Rub Nawaz, Dr. Rafique Ahmed, Sajida Reza

Figure 3.Identified criteria by healthcare experts via questionnaire 1.

\begin{tabular}{|c|c|c|}
\hline STRUCTURE & PROCESS & OUTCOME \\
\hline $\begin{array}{l}\text { - Clean environment } \\
\text { - Clean equipment } \\
\text { - Clear and wide entrance and exit } \\
\text { - Friendly staff } \\
\text { - Necessary medical equipment } \\
\text { - Qualified medical staff } \\
\text { - Reliable diagnostic labs } \\
\text { - Satisfactory staff-patient ratio }\end{array}$ & $\begin{array}{l}\text { - Accurate mention of service charges } \\
\text { - Avoidance of un-necessary patient stay at } \\
\text { - hospital } \\
\text { - Case history of patient } \\
\text { - Complete information about treatment } \\
\text { procedure } \\
\text { - Correct initial diagnosis } \\
\text { - Easy appointment } \\
\text { - Easy patient registration } \\
\text { - Knowledgeable staff } \\
\text { - Open to suggestions } \\
\text { - Prompt handling of complaints } \\
\text { - Prompt treatment procedure } \\
\text { - Proper maintenance of patient records } \\
\text { - Punctual consultation } \\
\text { - Satisfactory treatment } \\
\text { - Sympathetic attitude towards patients }\end{array}$ & $\begin{array}{l}\text { - Affordable service } \\
\text { - Effective treatment } \\
\text { - Future preference of treatment } \\
\text { - Referrals to other patients }\end{array}$ \\
\hline
\end{tabular}

Figure 4. Hierarchical structure of Quality Care criteria importance by patients.

GOAL

FACTORS

VARIABLES

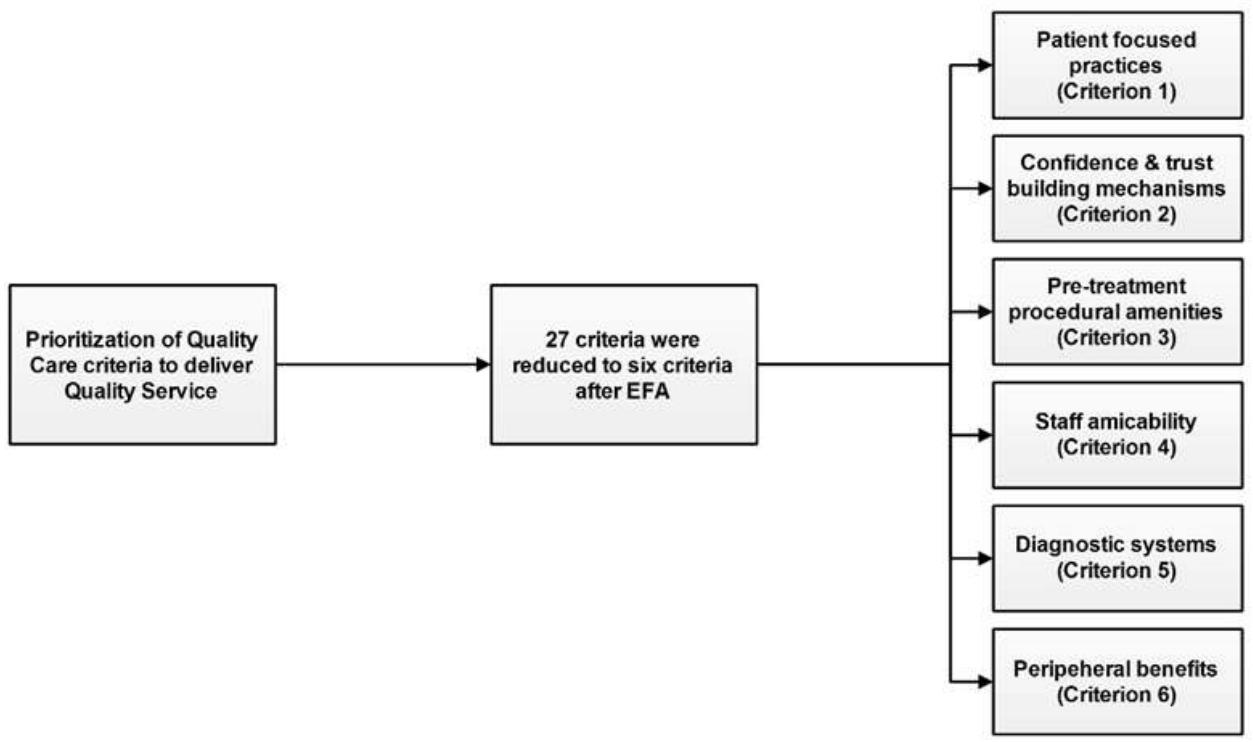


PRIORITIZATION OF QUALITY CARE CRITERIA TO DELIVER QUALITY SERVICE USING DEMATEL

Figure 5. DEMATEL digraph showing prioritization of Quality Care criteria

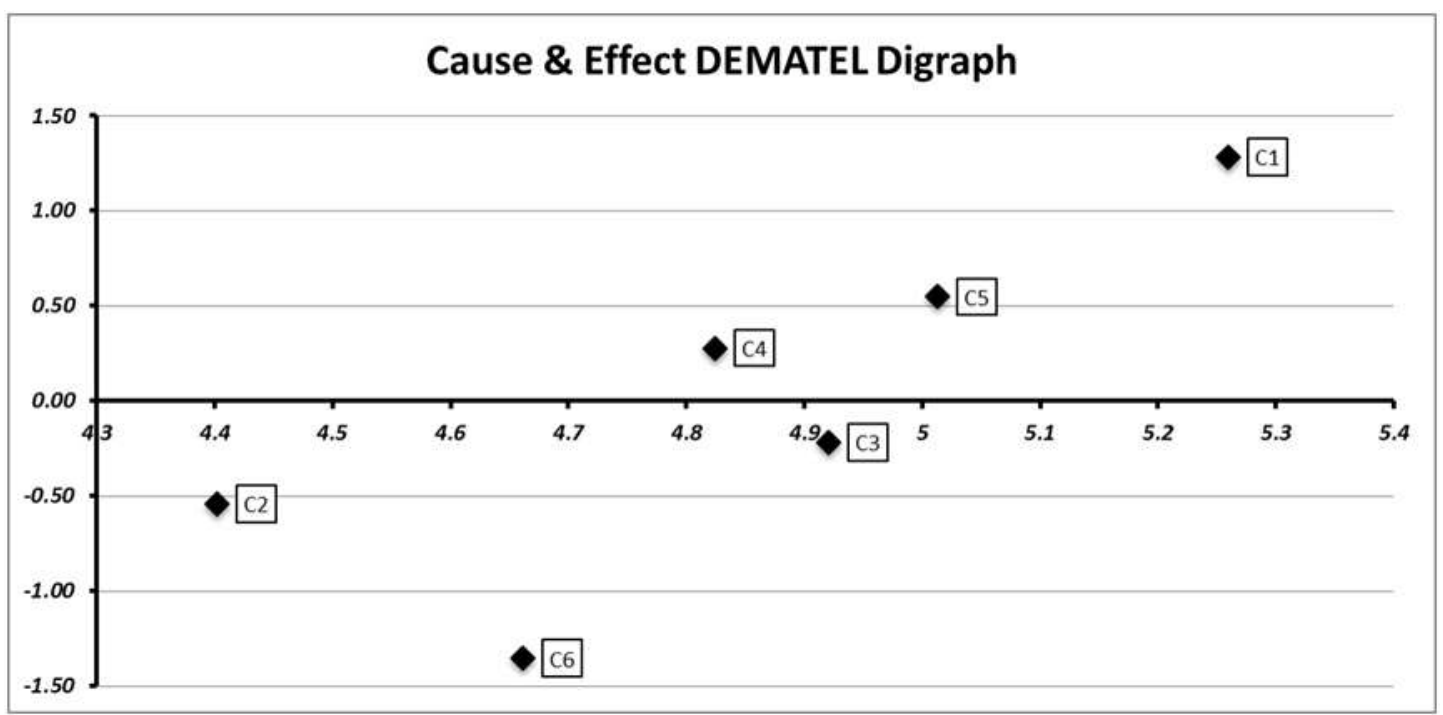

Figure 6. DEMATEL digraph overlaid with cause and effect arrows on criteria

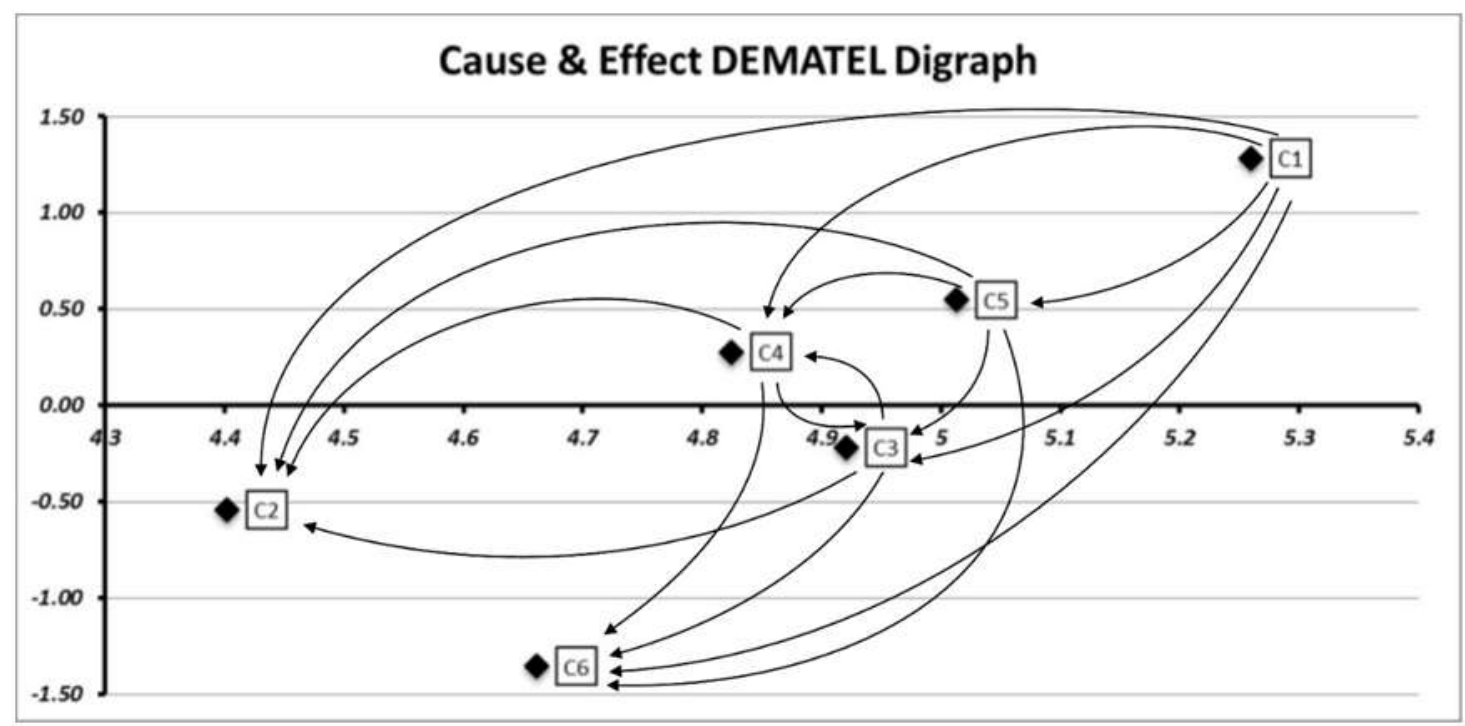


Table 1

Influence scale for DEMATEL questionnaire (Q3).

Influence Scale

Ratings

Extremely High Influence

4

High Influence

3

Moderate Influence

2

Little Influence

1

No Influence

0

Table 2

The Influence Matrix (Expert 1 only).

\begin{tabular}{lcccccc}
\hline \multirow{2}{*}{ CRITERIA } & Criterion & Criterion & Criterion & Criterion & Criterion & Criterion \\
& 1 & 2 & 3 & 4 & 5 & 6 \\
\hline Criterion 1 & 0 & 4 & 4 & 2 & 4 & 3 \\
Criterion 2 & 1 & 0 & 1 & 2 & 2 & 1 \\
Criterion 3 & 1 & 2 & 0 & 4 & 2 & 4 \\
Criterion 4 & 3 & 2 & 3 & 0 & 2 & 3 \\
Criterion 5 & 2 & 4 & 2 & 4 & 0 & 4 \\
Criterion 6 & 1 & 1 & 2 & 2 & 2 & 0 \\
\hline
\end{tabular}

Table 3

The average matrix $\boldsymbol{A}$.

\begin{tabular}{lcccccc}
\hline \multirow{2}{*}{ CRITERIA } & Criterion & Criterion & Criterion & Criterion & Criterion & Criterion \\
& 1 & 2 & 3 & 4 & 5 & 6 \\
\hline Criterion 1 & 0 & 3.47 & 3.33 & 3.27 & 3.80 & 3.13 \\
Criterion 2 & 2.00 & 0 & 2.00 & 1.33 & 2.13 & 1.80 \\
Criterion 3 & 2.00 & 2.00 & 0 & 2.87 & 1.73 & 3.33 \\
Criterion 4 & 2.53 & 2.33 & 2.80 & 0 & 1.93 & 3.40 \\
Criterion 5 & 1.47 & 3.73 & 2.80 & 2.93 & 0 & 3.87 \\
Criterion 6 & 1.67 & 1.20 & 2.13 & 1.13 & 1.67 & 0 \\
\hline
\end{tabular}


Table 4

The normalized matrix $\boldsymbol{D}$.

\begin{tabular}{lcccccc}
\hline \multirow{2}{*}{ CRITERIA } & Criterion & Criterion & Criterion & Criterion & Criterion & Criterion \\
& 1 & 2 & 3 & 4 & 5 & 6 \\
\hline Criterion 1 & 0 & 0.204 & 0.196 & 0.192 & 0.224 & 0.184 \\
Criterion 2 & 0.118 & 0 & 0.118 & 0.078 & 0.125 & 0.106 \\
Criterion 3 & 0.118 & 0.118 & 0 & 0.169 & 0.102 & 0.196 \\
Criterion 4 & 0.149 & 0.137 & 0.165 & 0 & 0.114 & 0.200 \\
Criterion 5 & 0.086 & 0.220 & 0.165 & 0.173 & 0 & 0.227 \\
Criterion 6 & 0.098 & 0.071 & 0.125 & 0.067 & 0.098 & 0 \\
\hline
\end{tabular}

Table 5

Total influence matrix $\boldsymbol{T}$.

\begin{tabular}{lcccccc}
\hline \multirow{2}{*}{ CRITERIA } & Criterion & Criterion & Criterion & Criterion & Criterion & Criterion \\
& 1 & 2 & 3 & 4 & 5 & 6 \\
\hline Criterion 1 & 0.332 & 0.585 & 0.594 & 0.542 & 0.558 & 0.659 \\
Criterion 2 & 0.301 & 0.246 & 0.359 & 0.300 & 0.333 & 0.393 \\
Criterion 3 & 0.345 & 0.397 & 0.308 & 0.415 & 0.359 & 0.527 \\
Criterion 4 & 0.389 & 0.439 & 0.476 & 0.295 & 0.393 & 0.560 \\
Criterion 5 & 0.363 & 0.528 & 0.502 & 0.463 & 0.311 & 0.612 \\
Criterion 6 & 0.257 & 0.276 & 0.329 & 0.258 & 0.278 & 0.256 \\
\hline
\end{tabular}

Table 6

Total effects to create the DEMATEL digraph.

\begin{tabular}{lcccc}
\hline CRITERIA & $g$ & $r$ & $\boldsymbol{p}=g+r$ & $\boldsymbol{q}=g-r$ \\
\hline Criterion 1 & 3.27 & 1.99 & 5.26 & 1.28 \\
Criterion 2 & 1.93 & 2.47 & 4.40 & -0.54 \\
Criterion 3 & 2.35 & 2.57 & 4.92 & -0.22 \\
Criterion 4 & 2.55 & 2.27 & 4.82 & 0.28 \\
Criterion 5 & 2.78 & 2.23 & 5.01 & 0.55 \\
Criterion 6 & 1.65 & 3.01 & 4.66 & -1.35 \\
\hline
\end{tabular}

